\title{
Training System Affects Sweet Cherry Harvest Efficiency
}

\author{
Yiannis G. Ampatzidis ${ }^{1}$ \\ Center for Precision and Automated Agricultural Systems, Washington State \\ University, 24106 N. Bunn Road, Prosser, WA 99350
}

Matthew D. Whiting

Department of Horticulture, Washington State University, 24106 N. Bunn Road, Prosser, WA 99350

Additional index words. harvest labor, tree architecture, precision farming, RFID, payroll, harvest rate

\begin{abstract}
Intuitively, tree architecture will affect harvest efficiency of tree fruit crops, yet there are no empirical studies that document this. The objective of the current research was to investigate the role of training system on harvest rate of individual pickers in commercial sweet cherry (Prunus avium L.) orchards. We used a real-time labor monitoring system (LMS) with the ability to track and record individual picker efficiency in 11 orchards throughout the Pacific Northwest. Trees were trained to one of five different architectures: 1) upright fruiting offshoots (UFO), a planar architecture comprised of unbranched vertical fruiting wood; 2) Y-trellised, an angled dual planar architecture; 3) Kym Green Bush (KGB), a multileader bush; 4) central leader (CL); and 5) traditional multileader open center (MLOC), trees comprised of three to five main leaders. A consistent picking crew was used to facilitate comparisons among systems and eliminate variability in skill among pickers. The LMS calculated harvest rate, picking cost, weight of harvested fruit, number of harvested buckets, range in fruit weight per bucket/bin, and mean fruit weight per bucket/bin for individual pickers. Tests revealed a significant effect of canopy architecture on labor efficiency. The highest mean ( \pm SE) harvest rates $\left(0.94 \pm 0.02 \mathrm{~kg} \cdot \mathrm{min}^{-1}\right.$ and $\left.0.78 \pm 0.03 \mathrm{~kg} \cdot \mathrm{min}^{-1}\right)$ were recorded in 'Cowiche'/'Gisela ${ }^{\circledR} 5$ ' and 'Tieton'/'Gisela ${ }^{\circledR} 5$ ' orchards trained to the UFO system, respectively. High harvest efficiency in these orchards was likely the result of the planar, simplified architecture and that most fruit were accessible from the ground. The third highest picking rate was recorded in the KGB system $\left(0.73 \pm 0.04 \mathrm{~kg} \cdot \mathrm{min}^{-1}\right)$, a fully pedestrian orchard. Interestingly, harvest rate of slower pickers was improved to a greater extent $(+132 \%)$ than skilled pickers $(+83 \%)$ when comparing pedestrian and planar systems (e.g., UFO and KGB) with traditional architecture (MLOC). Furthermore, picking rate of individual pickers varied within 1 day by more than $100 \%$, likely as a result of variability in fruit density within trees, tree size as well as fruit accessibility. We documented variability of more than $35 \mathrm{~kg}$ in final bin weight across all orchards and a range in bucket weight between $\approx 7$ and $13 \mathrm{~kg}$. These results suggest that architecture has a major effect on harvest efficiency and that current systems of piece-rate picker reimbursement are beset with inaccuracy.
\end{abstract}

The harvest process for most fresh-market tree fruit crops is labor-intensive and timeconsuming. For sweet cherry (Prunus avium L.), harvest costs generally account for $50 \%$

\footnotetext{
Received for publication 18 Sept. 2012. Accepted for publication 11 Feb. 2013.

This research was supported in part by Washington State University Agricultural Research Center federal formula funds, Project No. WNP0745, No. WNP0728, and No. WNP0420 received from the U.S. Department of Agriculture National Institutes for Food and Agriculture, USDA-Specialty Crop Research Initiative project 2009-02559, Washington State University Center for Precision \& Automated Agricultural Systems.

Any opinions, findings, conclusions, or recommendations expressed in this publication are those of the author(s) and do not necessarily reflect the view of the U.S. Department of Agriculture.

${ }^{1}$ To whom reprint requests should be addressed; e-mail yiannis.ampatzidis@wsu.edu.
}

fresh-market consumption are currently harvested manually (Seavert et al., 2008).

Manually harvesting sweet cherries is one of the most labor-intensive of all agricultural endeavors as a result of large tree size, high number of fruit per tree, and small fruit size. During harvest, laborers move along rows picking fruit with a slight twisting-snapping motion, removing fruit by the pedicel in clusters of one to four. Fruit are placed into metal or plastic buckets $(\approx 9 \mathrm{~kg}$ capacity) that are secured over their shoulders with strapping. When necessary to access fruit, aluminum ladders, ranging in height from 2.4 to $4 \mathrm{~m}$, are carried and used by pickers. When the picking bucket is full, pickers dump fruit into a larger receptacle (either a plastic lug or bin designed to hold $\approx 11.60 \mathrm{~kg}$ or $180 \mathrm{~kg}$, respectively). When used, full lugs are dumped subsequently into bins, and bins are collected by tractor, loaded on a trailer, and delivered to a local packing shed for sorting, cleaning, and packaging.

Intuitively, there are many factors that will affect harvest efficiency. These may be biological, technological, and sociological, yet there are limited empirical reports of their impact in tree fruit. Among others, tree architecture and age, fruit load, and picker skill are important factors affecting harvest efficiency (Ampatzidis et al., 2012a; Strik and Buller, 2002). Strik et al. (2003) found that pruning method affected hand harvest efficiency of blueberries ('Bluecrop' and 'Berkeley'), in some cases by more than $50 \%$. New high-density training systems for sweet cherry have been introduced in an attempt to produce high-quality fruit and achieve earlier orchard productivity (Lang, 2005; Whiting et al., 2005; Whiting and Smith, 2007). Whiting (2009) described the UFO system, a planar architecture comprised of unbranched vertical wood designed to improve worker safety and harvest efficiency and facilitate the incorporation of mechanization and automation technologies. However, there are limited published reports on the role of canopy architecture on harvest labor efficiency and safety (Ampatzidis et al., 2012a). This is attributable in part to the complexity of collecting reliable data in the field during hand harvest. Data acquisition systems should be automated and timely, eliminate manual entry of data, increase data accuracy, and prevent employee fraud (Ampatzidis, 2010; Ampatzidis et al., 2008).

Various approaches to, and systems for, data collection in orchards such as yield monitoring systems for citrus (Salehi et al., 2000; Schueller et al., 1999; Whitney et al., 1999), in-field traceability systems based on radio frequency identification (RFID) and barcodes registration technologies (Ampatzidis and Vougioukas, 2009; Ampatzidis et al., 2009), tree identification systems (Bowman, 2010; Luvisi et al., 2010, 2011), wearable systems for tracing and locating workers (Ampatzidis et al., 2011) as well as wireless and mobile acquisition devices (Cunha et al., 2010; Kuflik et al., 2009; Morais et al., 2008) have been developed and field-tested. A prototype 


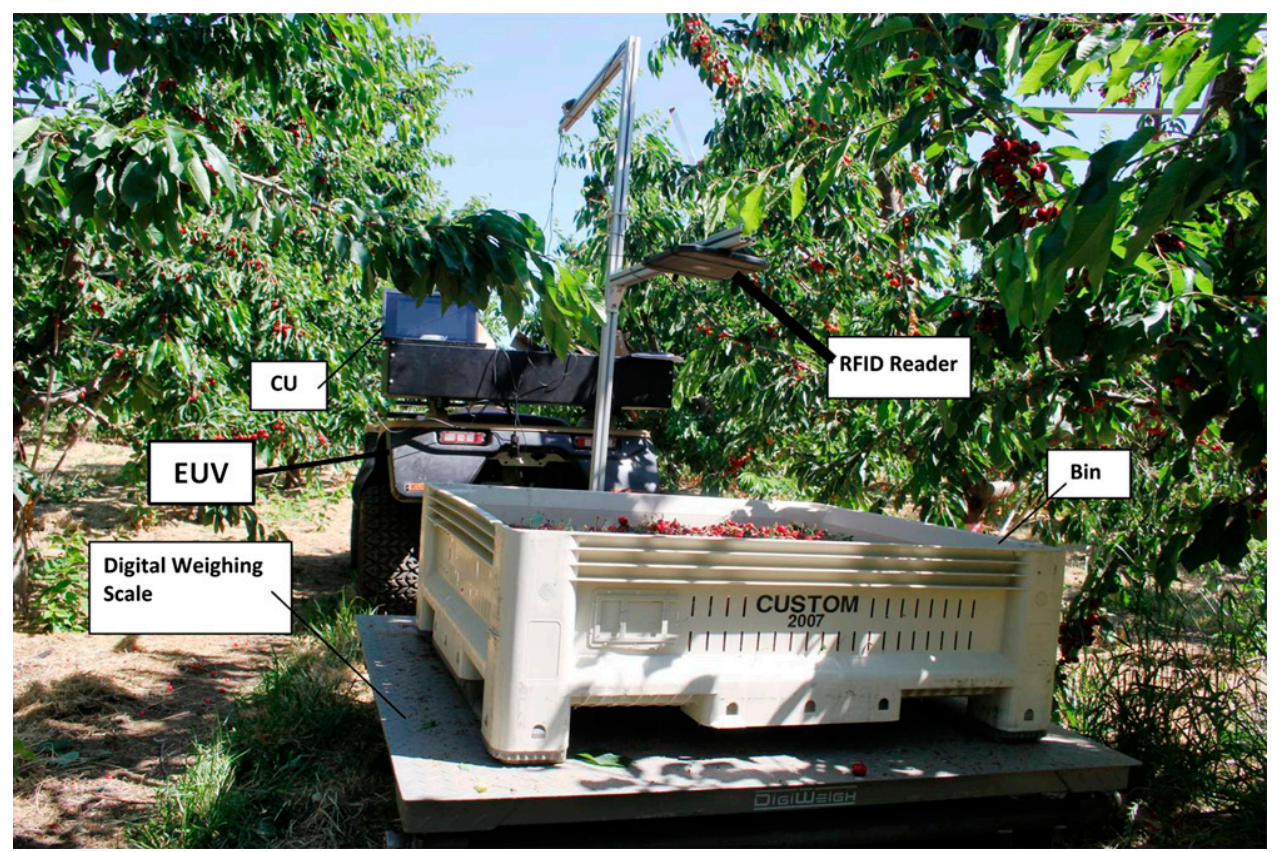

Fig. 1. Prototype system for monitoring picker efficiency. $\mathrm{CU}=$ computational unit; EUV = electrical utility vehicle; RFID = radiofrequency identification.

system for measuring average harvest efficiency, per picking crew, was developed in 2010 (Ampatzidis et al., 2012a) and modified in 2011 (Ampatzidis et al., 2012b) to a realtime LMS with the ability to track and record individual picker efficiency. In the current study, the LMS was used to investigate the role of tree architecture on picker efficiency during sweet cherry harvest in commercial orchards.

\section{Materials and Methods}

Labor monitoring system. A LMS was used to evaluate the role of training systems in harvest efficiency. Tests show that the LMS does not interfere significantly with the commercial harvest process (Ampatzidis et al., 2012b). This system consists of 1) a digital weighing scale; 2) a RFID reader; 3 ) a computational unit; and 4) a wearable data logger (Ampatzidis et al., 2012b). The RFID reader, the digital scale, and the computational unit were assembled on a chassis as a portable unit (Fig. 1) and RFID tags containing unique ID numbers embedded within rubber wrist bands were worn by pickers. A standard harvest bin $(1.22 \times 1.22 \times 0.3 \mathrm{~m})$ was centered on the scale to collect fruit as pickers emptied their harvest buckets. The LMS can simultaneously read a picker ID (RFID tag), measure the weight of fruit, and record the time of every fruit drop as pickers emptied their buckets directly into bins. The accumulated fruit weight is transmitted wirelessly, through a Zigbee wireless transceiver $(2.4 \mathrm{GHz}$, Sparkfun Electronics, USA), to the picker's data logger, which records and displays, through LCD, the total weight of harvested fruit. An electric utility vehicle (Fig. 1) was used to move the LMS within the orchards. The capacity of the digital commercial scale is $4530 \mathrm{~kg}$ (resolution of $0.5 \mathrm{~kg}$ ) and the operation range of the RFID reader/writer (Model 233004 by GAO RFID Inc., Canada; Fig. 1), that operates at $13.56 \mathrm{MHz}$ high frequency and reads multiple tags (ISO 15693 compliant transponders), is up to $30 \mathrm{~cm}$. A detailed description of the system is given in Ampatzidis et al. (2012b).

Experimental design. Testing was conducted throughout the Yakima Valley and Columbia Basin (Washington) and in The Dalles (Oregon) area. Harvest efficiency was studied in 11 commercial sweet cherry orchards (Fig. 2) trained to one of five different architectures: 1) UFO, a planar architecture comprised of unbranched vertical fruiting wood; 2) Y-trellised, an angled dual planar architecture; 3) KGB, a multileader bush; 4) $\mathrm{CL}$; and 5) MLOC, low density of trees comprised of three to five main leaders. To eliminate variability among pickers, a consistent commercial picking crew was used (Table 1) in each orchard. In addition, when possible, local pickers from the orchardists' crews were used in some orchards to compare with our picking crew (Table 2). Table 3 presents pertinent details of the 11 orchards; more details regarding the harvest process are described subsequently for some orchards where the harvest process and/or the experimental design differed from the traditional process.

The first orchard, near Benton City, WA, was comprised of five-year-old 'Tieton'/ 'Gisela ${ }^{\circledR} 5$ ' trees. On 28 June, 2011, 16 pickers harvested fruit from four rows of trees (two on either side of the bin) using 3-m ladders. Three RFID tags were worn by the first three Washington State University (WSU) pickers (Table 1) and one by a picker from the grower's crew (Table 2 ) to calculate their individual picking efficiency. The other 12 pickers were pooled to estimate their average harvest rate using one RFID tag for them all. Harvest began at $0505 \mathrm{HR}$ and
Table 1. WSU commercial picking crew ("WSU crew") characteristics.

\begin{tabular}{lcccc}
\hline & \multicolumn{4}{c}{ Picker } \\
\cline { 2 - 5 } Characteristics & First & Second & Third & Fourth \\
\hline Sex & $\mathrm{F}$ & $\mathrm{F}$ & $\mathrm{F}$ & $\mathrm{F}$ \\
Age & 17 & 42 & 40 & 43 \\
Experience (years) & 7 & 15 & 5 & 7 \\
\hline
\end{tabular}

$\mathrm{WSU}=$ Washington State University; $\mathrm{F}=$ female.

finished at $0758 \mathrm{HR}$ when the crew moved to an adjacent orchard.

At the second orchard, contiguous to the first, the pay rate was $\$ 2.75$ per bucket; pickers used 3-m ladders and harvested along four contiguous rows with pickers in the outside rows having to pass their buckets to the bin checker because of trellis wires. The same picking crew as the first orchard was used and they started harvest at $0806 \mathrm{HR}$ finishing at $1132 \mathrm{HR}$.

At the third and fourth orchard, the same picking crew was used (three WSU pickers and one picker from the grower's crew). They harvested in the third orchard between 0710 HR and 1003 HR using 3-m ladders and then moved to the fourth orchard.

The sixth orchard was overcropped with an abundance of small fruit per tree. In Orchard 9 on 28 July 2011 five pickers (three "WSU pickers"- first, second, and fourthand two from the grower's crew; Table 2) harvested nine bins (using 3-m ladders). Additionally, in Orchard 10 , trees were planted in double rows at $4.3-\mathrm{m}$ spacing within a row and $3 \mathrm{~m}$ between rows. The spacing between the double tree rows was $0.9 \mathrm{~m}$. The number of trees per acre was 520 .

\section{Results and Discussion}

The LMS was effective at calculating the harvest rate, picking cost, weight of harvested 
fruit, number of harvested buckets, range in fruit weight per bucket, and mean fruit weight per bucket. As harvested fruit were dumped into a standard collection bin, the LMS read the picker's ID (RFID tag) and recorded and plotted in real time the incremental weight of fruit. Identifying each picker's ID with the RFID technology was reliable throughout testing. Pickers' tags were detected successfully in every orchard; there were no erroneous records detected. Using data from the LMS, it is possible to assess harvest efficiency metrics in detail, including weight of harvested fruit for individual pickers and every bin over time (e.g., Fig. 3). Picker harvest rate ( \pm SE of means) was calculated as the fraction of the total weight of harvested fruit per individual picker divided by the actual working time (after deducting time for breaks).

The mean harvest rate among orchards and pickers varied tremendously (Table 4). The mean harvest rates (mean of two, mean of three, mean of four; Tables 4 and 5) were calculated based on all the samples (harvest rate for each fruit drop for each picker) and not based only on the mean values (harvest rates) of each picker [e.g. Orchard 1, mean of two is not: $(0.50+0.86) / 2=0.68 \mathrm{~kg} \cdot \mathrm{min}^{-1}$; all the data-harvest rates for each fruit drop were used to calculate the mean of $2=0.72$ $\mathrm{kg} \cdot \mathrm{min}^{-1}$ and the $\left.\mathrm{SE}= \pm 0.05\right]$.

In the first and second orchard, the "sixth picker" represents the average harvest rate of 12 additional pickers; one RFID tag was used for all of them and when any picker from this group dumped fruit into the bin, the same ID tag was used to assign the fruit. When possible, the harvest rate of the grower's commercial crew was calculated for comparison with the mean harvest rate of the WSU crew. For example, in Orchard 1 (13 additional pickers were used in this orchard with mean harvest rate $0.67 \mathrm{~kg} \cdot \mathrm{min}^{-1}$ ), Picker 2 of the WSU crew was above the additional pickers' average harvest rate $(+28 \%)$, whereas Pickers 1 and 3 were below $(-26 \%$ and $-15 \%$, respectively). In Orchard 2 (13 additional pickers with mean harvest rate was above the additional pickers' average harvest rate $(+9 \%)$, whereas Pickers 1 and 3 were below ( $-13 \%$ and $-17 \%$, respectively). In Orchard 11 (five additional pickers with mean harvest rate $0.98 \mathrm{~kg} \cdot \mathrm{min}^{-1}$ ), Pickers 1 and 2 of the WSU crew were below the additional pickers' average harvest rate ( $-40 \%$ and $-21 \%$, respectively). Nevertheless, the WSU pickers were within the range of picking efficiency of the pickers from commercial crews (WSU crew had picked cherries previously in commercial orchards; $0.78 \mathrm{~kg} \cdot \mathrm{min}^{-1}$ ), Picker 2 of the WSU crew

Table 1). This demonstrates that the WSU crew was representative of commercial pickers' abilities in picking cherries.

Pickers 1 and 2 of the WSU crew harvested fruit in each of the 11 orchards (Tables 3 and 4$)$ and therefore their harvest rates ( \pm SE of means) facilitate comparisons among every orchard. These comparisons revealed a significant effect of canopy architecture on labor efficiency with a twofold range among orchards from $0.48 \mathrm{~kg} \cdot \mathrm{min}^{-1}$ to 0.94 $\mathrm{kg} \cdot \mathrm{min}^{-1}$. We do not attribute the entirety of this variability to canopy architecture differences alone but do contend that canopy architecture was the major influence on harvest efficiency. The highest mean harvest rate $\left(0.94 \pm 0.02 \mathrm{~kg} \cdot \mathrm{min}^{-1}\right)$ was recorded in a 'Cowiche'/'Gisela ${ }^{\circledR} 5$ ' UFO orchard (seventh orchard) followed by another UFO orchard ('Tieton'/'Gisela ${ }^{\circledR} 5$ ', second orchard) at $0.78 \pm 0.03 \mathrm{~kg} \cdot \mathrm{min}^{-1}$. High harvest efficiency in these two orchards likely was the result of most fruit being harvested from the ground and the simplified planar architecture in which fruit were easily accessible. The third highest harvest rate $(0.73 \pm 0.04$ $\mathrm{kg} \cdot \mathrm{min}^{-1}$ ) was recorded in a KGB system (10th orchard). This orchard system's efficiency is likely the result of its pedestrian (i.e., harvesting required no ladders) nature. The improved harvest efficiency of a planar architecture (i.e., UFO) compared with a completely pedestrian system (i.e., KGB) suggests that ease of access to fruit is more important than eliminating ladders, although more research is needed to prove this conclusively.

The entire WSU picking crew of four harvested fruit in Orchards 5 to 8. Within these orchards, their combined highest harvest rate was in Orchard 7 (UFO) and the lowest in Orchard 6 (MLOC). Picker 1 exhibited a $51 \%$ lower harvest rate in the MLOC orchard $\left(0.39 \mathrm{~kg} \cdot \mathrm{min}^{-1}\right)$ compared with the UFO orchard $\left(0.79 \mathrm{~kg} \cdot \mathrm{min}^{-1}\right)$. In contrast, harvest efficiency for Picker 3 was only $12 \%$ lower in Orchard $6\left(0.56 \mathrm{~kg} \cdot \mathrm{min}^{-1}\right)$ compared with Orchard $7\left(0.64 \mathrm{~kg} \cdot \mathrm{min}^{-1}\right)$. We hypothesize that the significant improvement in harvest rate of Picker 1 in the UFO orchard may be partly the result of her ineffectiveness working with the larger ladders that were required in the MLOC orchard. A picker with less ladder placement skills can improve significantly his or her picking efficiency in orchards where most fruit is accessible from the ground. In orchards where ladders were used most of the time (i.e., the MLOC orchards), harvest efficiency of Picker 1 was low because she spent a lot of time moving and placing the ladder. This underscores the importance of further

Table 2. Characteristics of the additional pickers (growers' crews).

\begin{tabular}{|c|c|c|c|c|c|c|c|c|c|c|c|c|c|}
\hline Orchard & First & Second & Third & Fourth & \multirow{2}{*}{\multicolumn{2}{|c|}{$\frac{\text { Ninth }}{2}$}} & \multicolumn{2}{|c|}{ 10th } & \multicolumn{5}{|c|}{ 11th } \\
\hline Additional pickers & 1 & 1 & 1 & 1 & & & & & & & 5 & & \\
\hline Sex & M & $\mathrm{M}$ & $\mathrm{M}$ & M & M & $\mathrm{F}$ & M & $\mathrm{M}$ & $\mathrm{M}$ & M & $\mathrm{M}$ & M & \\
\hline Age & 21 & 21 & 32 & 32 & 36 & 23 & 28 & 28 & 20 & 43 & 20 & 22 & $2 ?$ \\
\hline Experience (years) & 6 & 6 & 12 & 12 & 19 & 6 & 10 & 10 & 5 & 15 & 5 & 9 & \\
\hline
\end{tabular}

$\mathrm{M}=$ male; $\mathrm{F}=$ female.

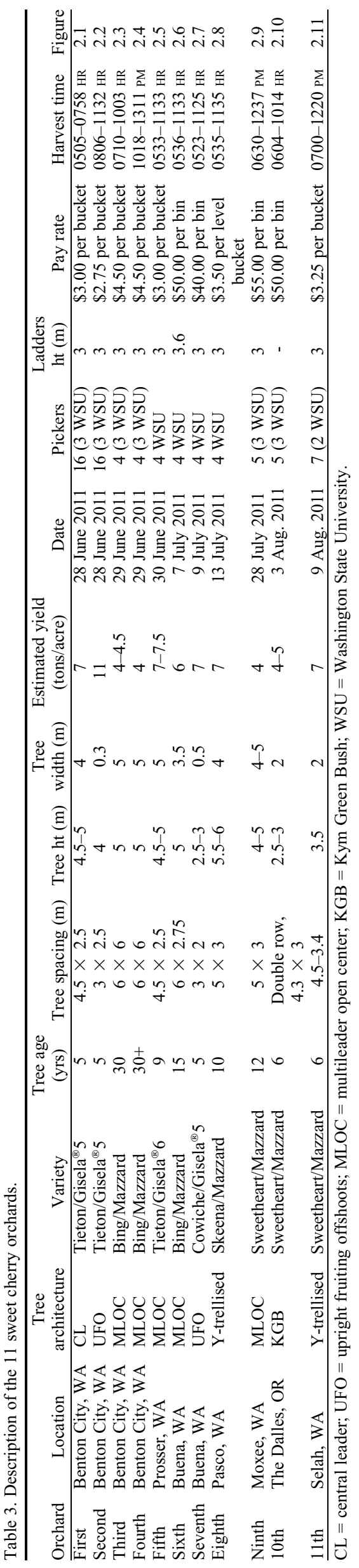



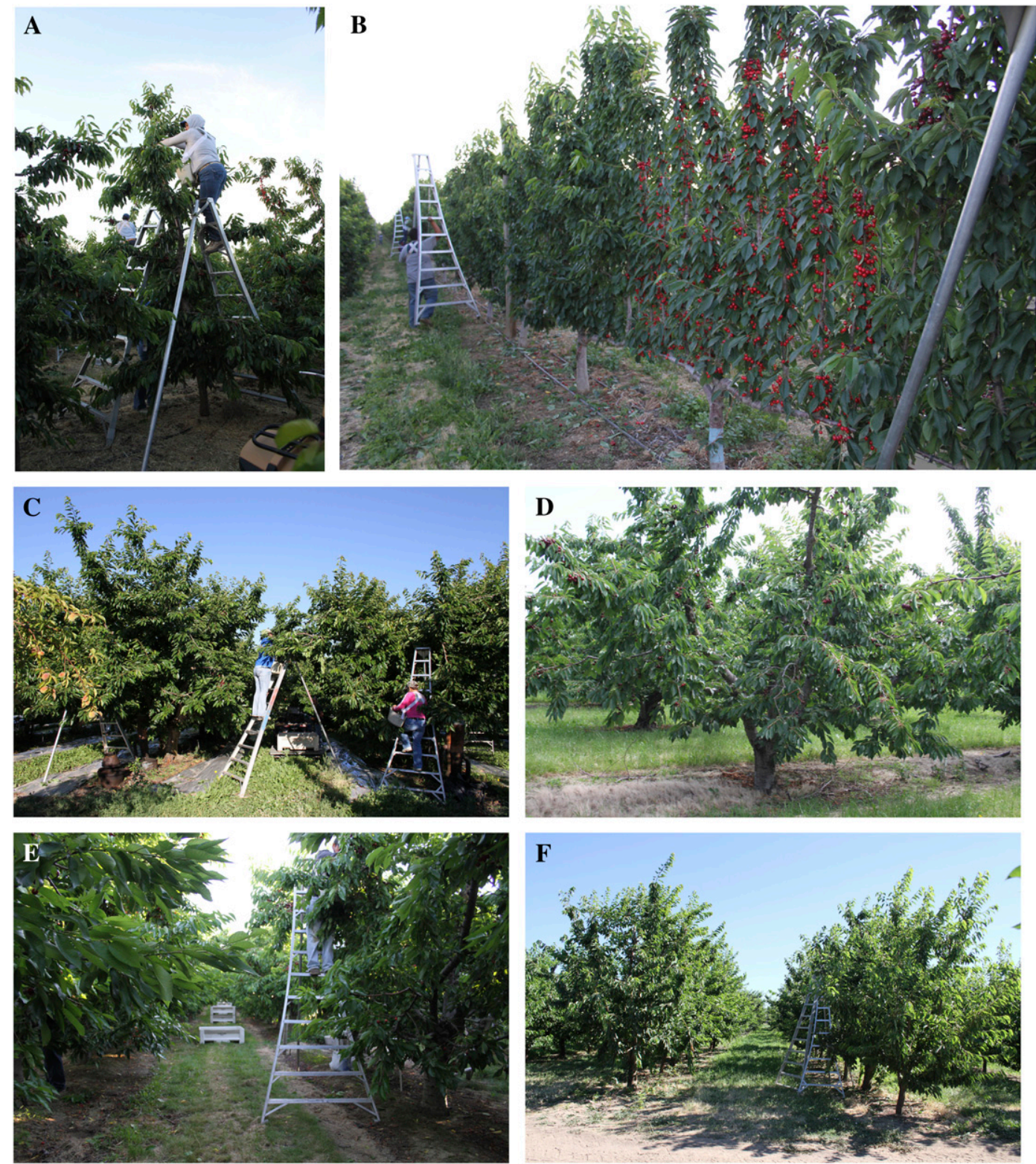

Fig. 2. Commercial sweet cherry orchards in which picker efficiency was studied: A) central leader near Benton City; B) UFO near Benton City; C) MLOC in Benton City; D) MLOCnear Benton City; E) MLOC near Prosser; F) MLOCnear Buena; G) UFO near Buena; H) Y-trellised near Pasco; I) MLOCnear Moxee; J) KGB near the Dalles; and K) Y-trellised near Selah. UFO = upright fruiting offshoots; MLOC = multileader open center; KGB = Kym Green Bush.

developing and adopting high-efficiency planar architectures in tree fruit, because increasing competition causes growers to hire less experienced picking crews.

To assess the effect of canopy architecture on the performance of each member of the WSU picking crew, picking rate in each orchard was compared with their highest harvest rate (Orchard 7 in every case; Table $5)$. For each picker, the variability in harvest rate among orchards is likely the result of several factors including canopy architecture, tree size, and fruit load. Harvest rate of less skilled pickers was reduced to a greater extent $(-67 \%)$ than skilled pickers $(-45 \%)$ when comparing efficiency in pedestrian and planar systems (e.g., UFO and KGB) with MLOC. For example, harvest rate of Picker 1, the least skilled picker in the WSU crew, was $\approx 45 \%$ to $65 \%$ lower in MLOC orchards (e.g.,
Orchards 4, 5, 6, and 8) compared with pedestrian and planar systems (e.g., UFO, $\mathrm{KGB}$ ). These differences are not likely related to yield because yield was not particularly high in these pedestrian orchards (Table 3 ), but more likely the result of the fruit being highly accessible with much being accessible from the ground in the UFO and KGB. Skilled pickers with excellent ladder placement skills were $\approx 30 \%$ to $45 \%$ less efficient when picking fruit in MLOC orchards compared with pedestrian systems (e.g., second picker; Table 5). The orchards with low picking efficiency (e.g., Orchards 4, 5, 6, 8, and 11) were similar, characterized by large tree size, although architecture was slightly different. In each of these orchards, pickers required 3- to 4-m ladders to access fruit and this ladder time reduced efficiency. Ladders per se were not the only factor reducing harvest efficiency; Orchard 2 (planar UFO architecture) required ladders, but the placement of the ladder was consistent along the row. Again, the benefits of improved harvest efficiency in orchards with simplified architectures will likely become increasingly important as growers rely on pickers with less experience. The slowest picker on the WSU crew harvested $0.79 \mathrm{~kg} \cdot \mathrm{min}^{-1}$ in the pedestrian UFO orchard (seventh), a rate nearly $24 \%$ faster than the rate of the fastest picker of the WSU crew averaged in the four MLOC systems.

Harvest rate for individual pickers varied within a day by more than $100 \%$ (Fig. 4). For example, within Orchard 6, harvest rate varied for Picker 1 (Fig. 4A) between 0.30 and $0.47 \mathrm{~kg} \cdot \mathrm{min}^{-1}$ (average $0.39 \pm 0.01 \mathrm{~kg} \cdot \mathrm{min}^{-1}$ ), for Picker 2 (Fig. 4B) between 0.43 and $0.87 \mathrm{~kg} \cdot \mathrm{min}^{-1}$ (average $0.65 \pm 0.02 \mathrm{~kg} \cdot \mathrm{min}^{-1}$ ), 

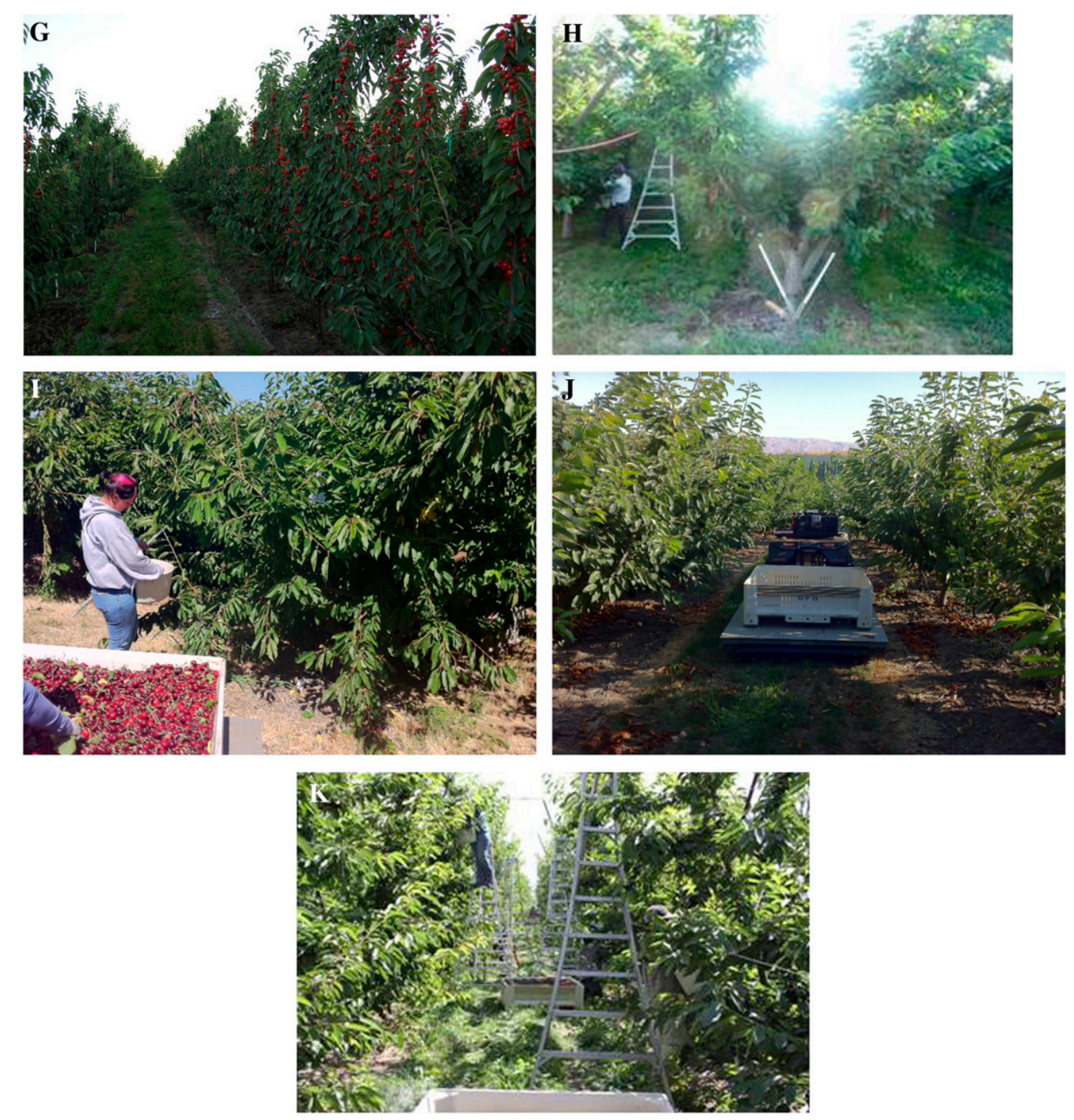

Fig. 2. Continued.

for Picker 3 (Fig. 4C) between 0.46 and 0.73 (average $0.56 \pm 0.01 \mathrm{~kg} \cdot \mathrm{min}^{-1}$ ), and for Picker 4 (Fig. 4D) between 0.38 and $0.74 \mathrm{~kg} \cdot \mathrm{min}^{-1}$ (average $0.55 \pm 0.02 \mathrm{~kg} \cdot \mathrm{min}^{-1}$ ). This range in picking rate from the same crew, within $1 \mathrm{~d}$ and in the same orchard, is likely the result of variability in fruit density within trees (i.e., light crop density may reduce efficiency), tree size as well as fruit accessibility (i.e., workers might pick fruit from ground or on ladders; they have to move ladders, climb, pick fruit, descend, and repeat this process). Interestingly, there was no apparent reduction in harvest efficiency during the day. Our complete analysis of the efficiency of individual pickers throughout the day (data not shown) has revealed no diurnal pattern whatsoever.

These data on harvest efficiency may be useful for growers planning personnel needs for harvest. The average yield in Washington State cherry orchards is estimated at 6 tons/ acre. At the highest recorded harvest rate $\left(0.94 \mathrm{~kg} \cdot \mathrm{min}^{-1}\right.$, mean of two), one picker could pick $451 \mathrm{~kg}$ per 8 -h shift, roughly equivalent to $8 \%$ of an acre. At the lower recorded harvest rate $\left(0.48 \mathrm{~kg} \cdot \mathrm{min}^{-1}\right.$, mean of two), one picker could pick only $230 \mathrm{~kg}$ in an 8 -h shift, or roughly equivalent to $4 \%$ of an acre. Harvesting 1 acre of sweet cherries with a 6-ton/acre yield in an 8-h shift would therefore require $\approx 24$ or 12 people at the lower or higher harvest rate, respectively, ceteris paribus.

Additional key attributes of harvest efficiency can be assessed using the LMS. These include final bin weight, number of buckets harvested per picker, mean (and range) weight of fruit from every dump into the bin, and the labor cost for picking based on the weight of harvested fruit per picker. There is significant variability among and within orchards for each of these elements (e.g., Table 6). For example, the range in harvested buckets and fruit weight per bucket varied significantly among pickers; in Orchard 7, the first picker harvested 16 buckets at $8.2 \pm 0.3 \mathrm{~kg} /$ bucket with a range between 6.5 and $9.0 \mathrm{~kg} /$ bucket, whereas the second picker harvested 22 buckets at $9.6 \pm 0.2 \mathrm{~kg} /$ bucket with a range between 7.5 and $13.0 \mathrm{~kg} /$ bucket (Table 6). In this orchard, pickers were paid $\$ 50 /$ bin and therefore, each picker earned $\$ 50$, because the crew of four harvested four bins. However, based on the actual weight that each picker harvested, the four pickers would have earned $\$ 36.6, \$ 60.4$, \$52.0, and \$51.0 (Table 6), respectively.

Generally, we documented significant variability in final bin weight-more than $35 \mathrm{~kg}$ across all orchards. This occurred despite efforts to fill the bins to a similar degree; identical bins were used in every orchard and pickers were instructed to fill them to a similar degree. This within-orchard variability may be, in part, attributed to the ability of the picking crew to judge when bins are full. Among orchards, however, this variability is likely the result of differences in fruit size because smaller fruit settle and pack better in the bins, causing heavier bins when full. In orchards where the picking crew was reimbursed per bin (e.g., Orchard 6), this variability leads to inaccurate reimbursement of pickers. In fact, in orchards where pickers 


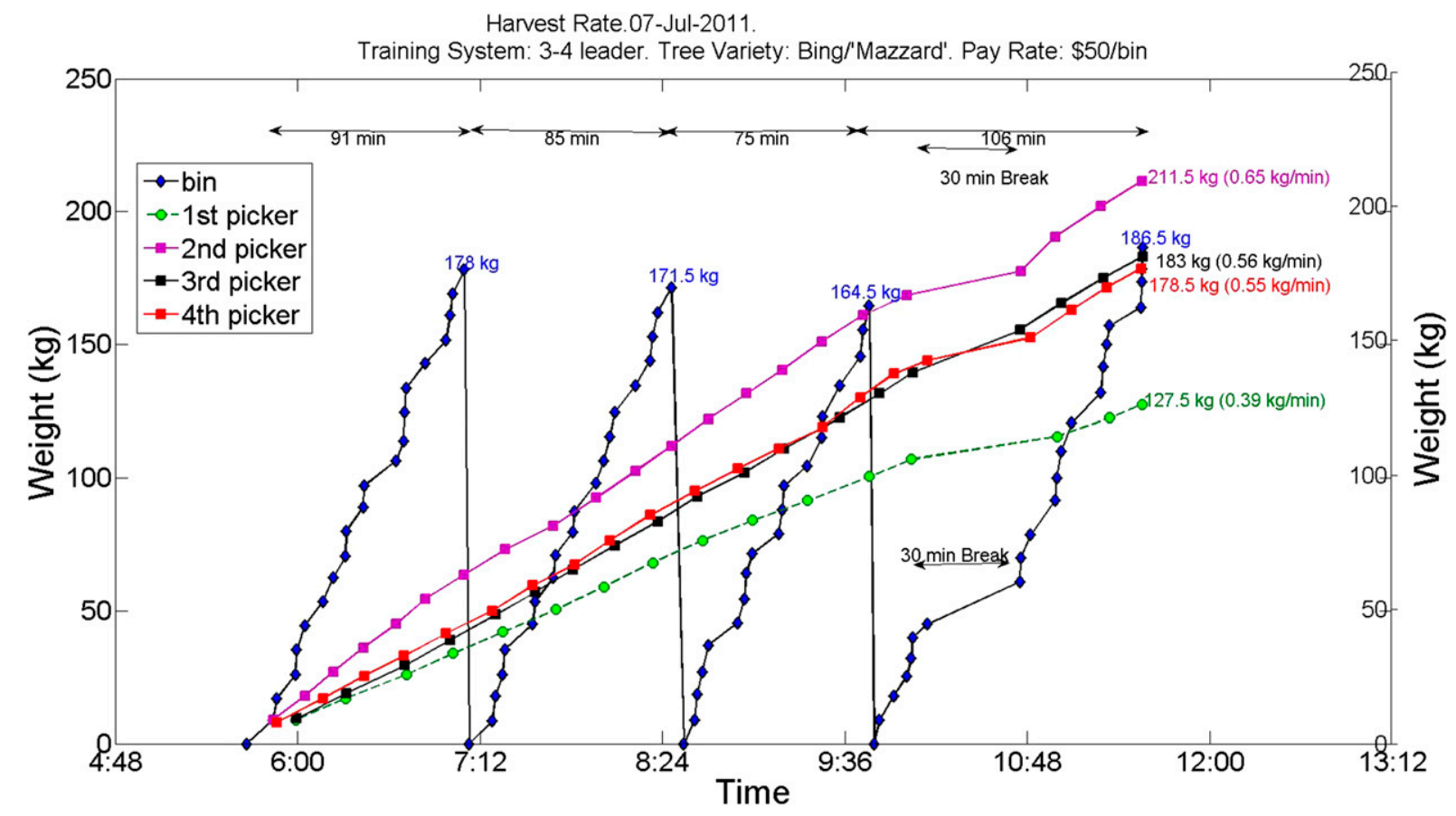

Fig. 3. Example of sweet cherry harvest data (output from the LMS) for a 'Bing'/Mazzard orchard picked on 7 July 2011. There were four pickers ("WSU crew") picking into the bin and the pay rate was $\$ 50$ per bin. LMS = labor monitoring system; WSU = Washington State University.

Table 4. Summary of the mean harvest rate $( \pm \mathrm{SE})$ for each orchard block.

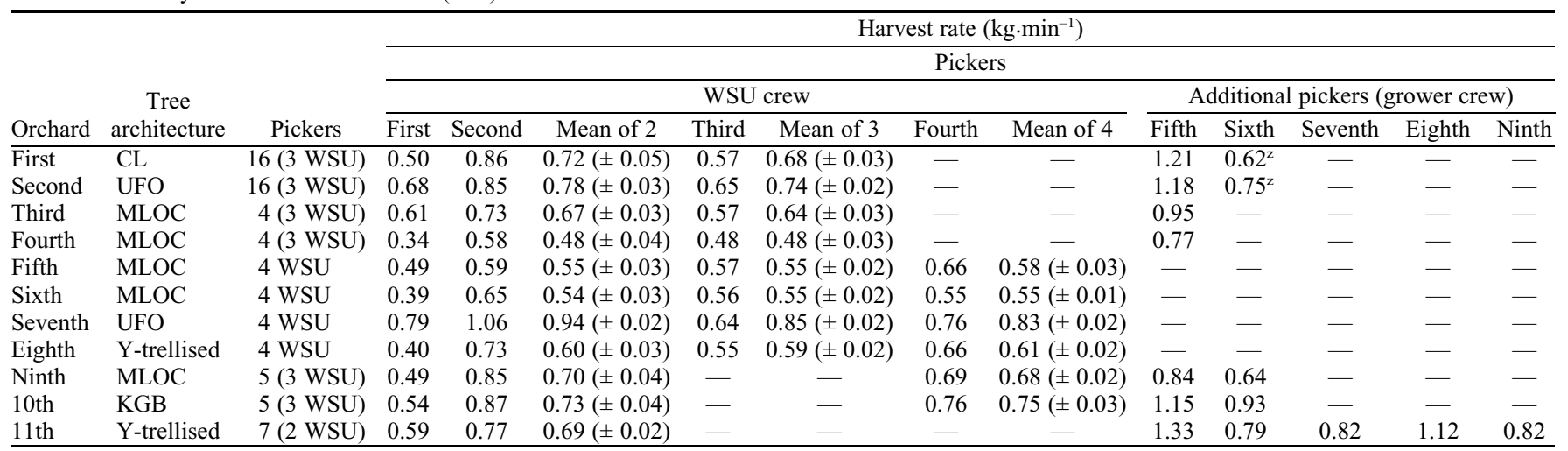

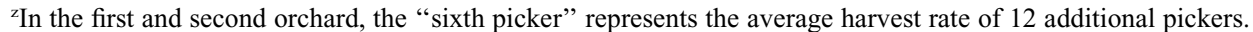

WSU = Washington State University; CL = central leader; UFO = upright fruiting offshoots; MLOC = multileader open center; KGB = Kym Green Bush.

Table 5. Mean harvest rate for each picker as a percentage of their performance in the fastest training system (UFO, seventh orchard)

\begin{tabular}{|c|c|c|c|c|c|c|c|c|c|}
\hline \multirow{3}{*}{ Orchard } & \multirow{3}{*}{$\begin{array}{c}\text { Tree } \\
\text { architecture }\end{array}$} & \multirow[b]{3}{*}{ Variety } & \multicolumn{7}{|c|}{ Harvest rate (\%) } \\
\hline & & & \multicolumn{7}{|c|}{ Pickers WSU crew } \\
\hline & & & First & Second & Mean of 2 & Third & Mean of 3 & Fourth & Mean \\
\hline First & $\mathrm{CL}$ & Tieton/Gisela ${ }^{\circledR} 5$ & 63 & 81 & 77 & 89 & 80 & - & - \\
\hline Second & UFO & Tieton/Gisela ${ }^{\circledR} 5$ & 86 & 80 & 83 & 102 & 87 & - & - \\
\hline Third & MLOC & Bing/Mazzard & 77 & 69 & 72 & 89 & 75 & - & - \\
\hline Fourth & MLOC & Bing/Mazzard & 43 & 55 & 51 & 75 & 56 & - & - \\
\hline Fifth & MLOC & Tieton/Gisela ${ }^{\circledR} 6$ & 62 & 56 & 59 & 89 & 65 & 87 & 70 \\
\hline Sixth & MLOC & Bing/Mazzard & 49 & 61 & 57 & 88 & 65 & 72 & 66 \\
\hline Seventh & UFO & Cowiche $/$ Gisela $^{\circledR} 5$ & 100 & 100 & 100 & 100 & 100 & 100 & 100 \\
\hline Eighth & Y-trellised & Skeena/Mazzard & 51 & 69 & 64 & 86 & 69 & 87 & 73 \\
\hline Ninth & MLOC & Sweetheart/Mazzard & 62 & 87 & 74 & - & - & 91 & 82 \\
\hline 10th & KGB & Sweetheart/Mazzard & 68 & 82 & 78 & - & - & 100 & 90 \\
\hline 11 th & Y-trellised & Sweetheart/Mazzard & 75 & 73 & 73 & - & - & - & - \\
\hline \multicolumn{3}{|c|}{ Mean } & 68 & 75 & 72 & 91 & 75 & 91 & 81 \\
\hline
\end{tabular}

UFO = upright fruiting offshoots; WSU = Washington State University; $\mathrm{CL}=$ central leader; $\mathrm{MLOC}=$ multileader open center; KGB = Kym Green Bush. were paid per bin, it is in pickers' best interest to minimize the quantity of fruit needed to fill the bin. Additionally, in orchards where pickers were paid per bucket (Orchards 1 to 5,8 , and 11 , we documented a range in fruit weight per bucket of between 7.0 and $13.0 \mathrm{~kg}$. At a pay rate of $\$ 3.00$ per bucket, the variability in bucket weight translates into a picking cost of $\$ 0.43$ to $\$ 0.23 / \mathrm{kg}$ at the lower and upper range of fruit weight per bucket, respectively. These results further underscore the inaccuracy with current systems of picker reimbursement. There is no industry standard for determining when bins or buckets are full. Generally bucket and bin volume are judged visually by the orchard manager or pickers with some understanding that overfilling is undesirable as a result of 


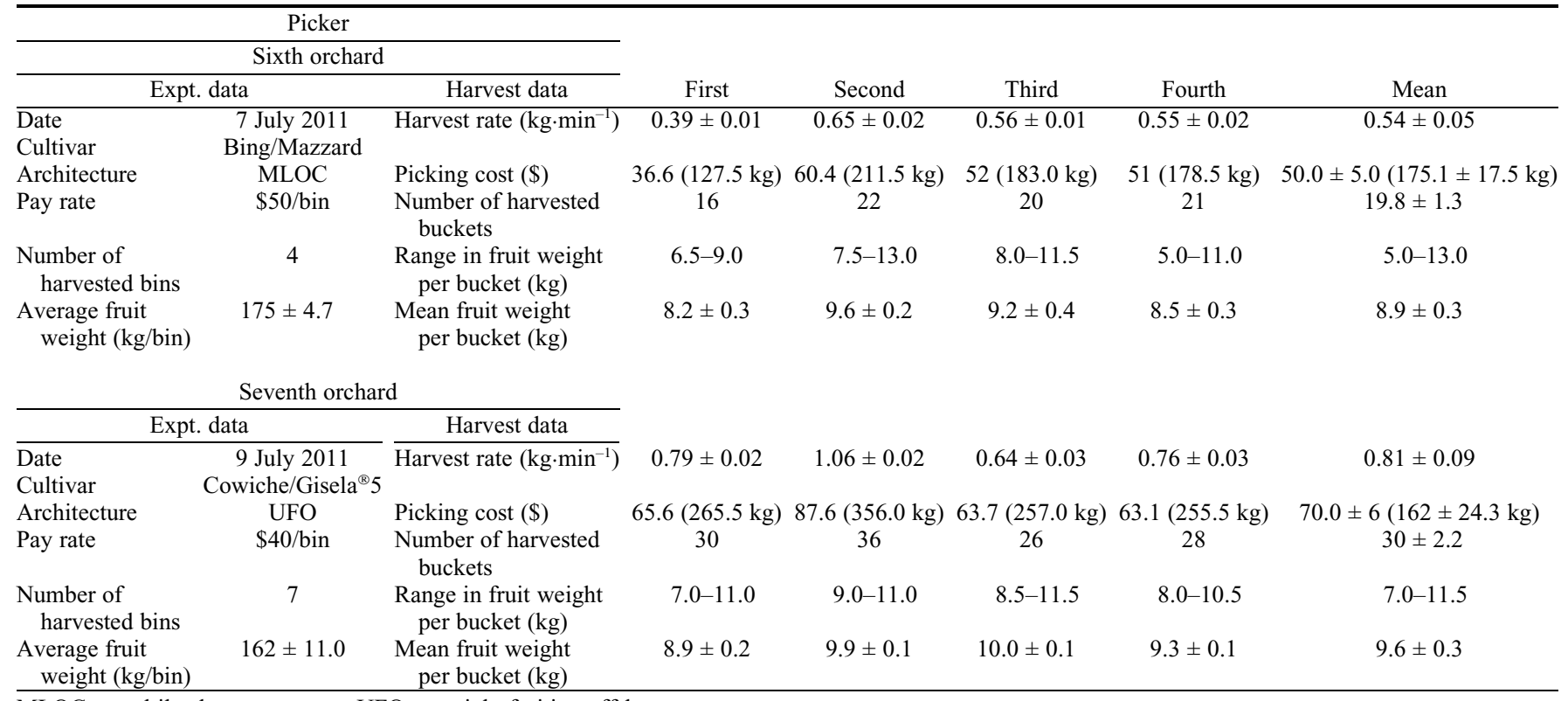

$\mathrm{MLOC}=$ multileader open center; UFO = upright fruiting offshoots.

$\mathbf{A}$

1st Picker. Harvest Rate Distribution

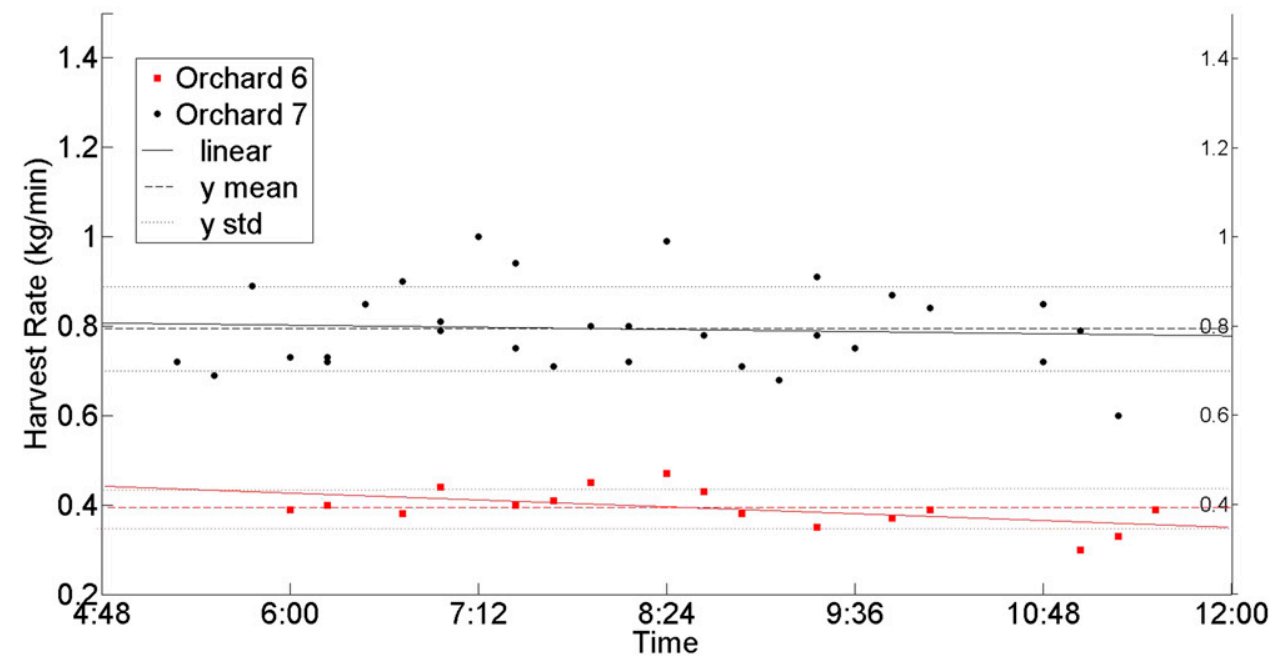

B

2nd Picker. Harvest Rate Distribution

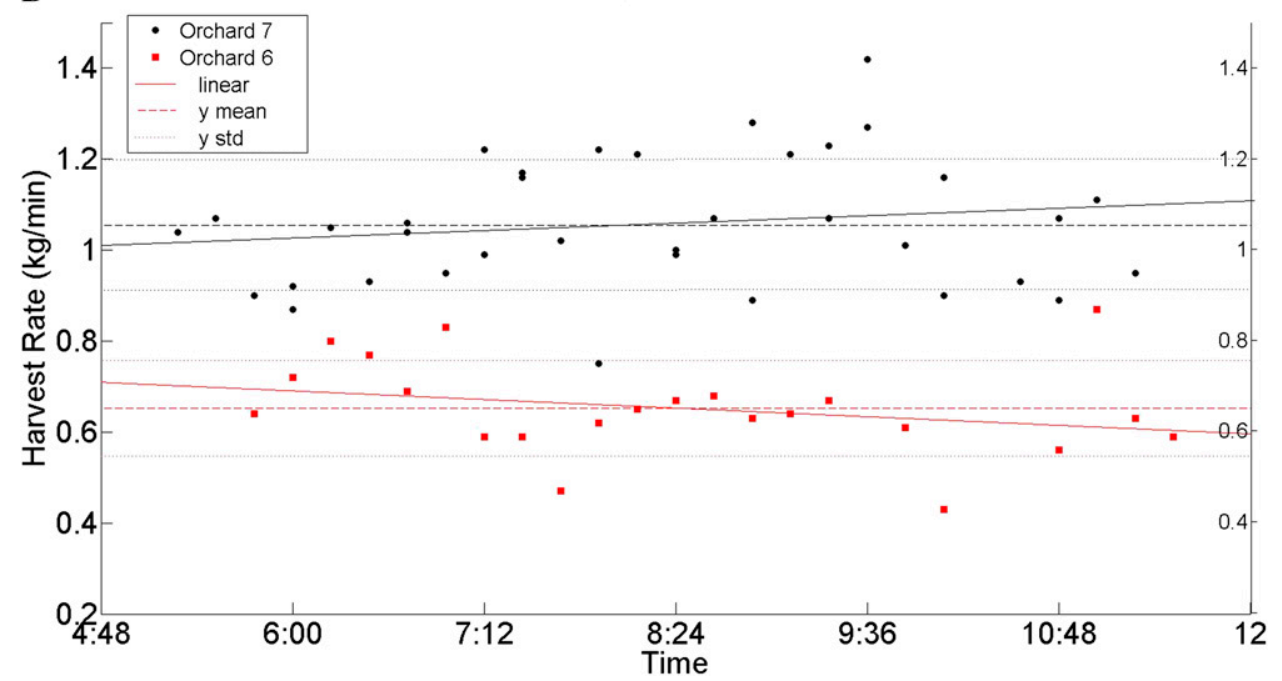

Fig. 4. Harvest rate distribution in Orchards 6 and 7 for (A) first, (B) second, (C) third, and (D) fourth picker. 


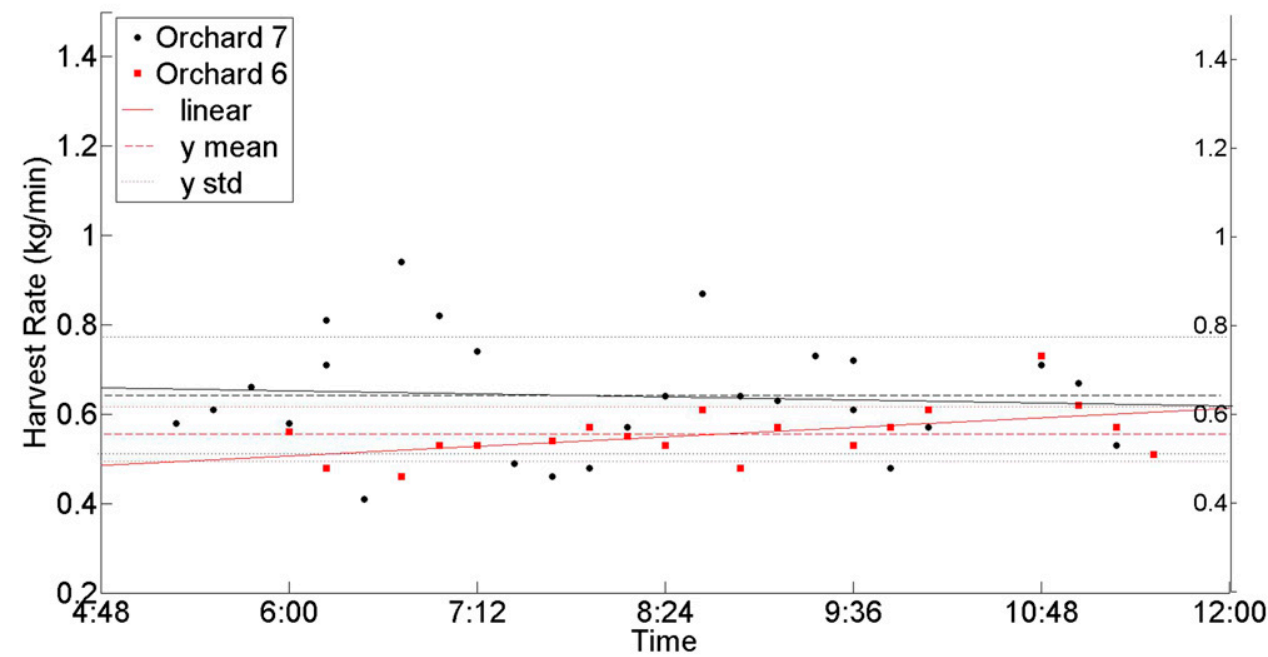

D

4th Picker. Harvest Rate Distribution

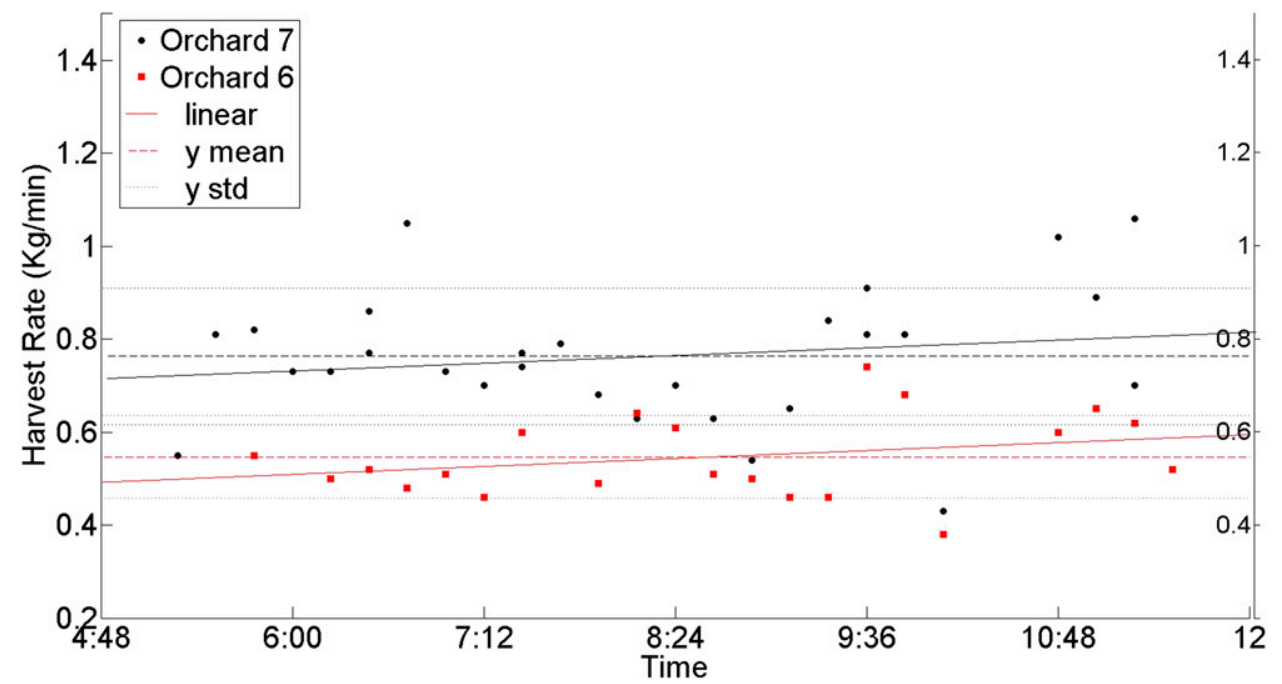

Fig. 4. Continued.

potential fruit damage. Furthermore, some pickers attempt to minimize the quantity of fruit in each bucket so they can pick more buckets and earn more money. Orchard managers indicated that the ability to track individual pickers' harvest rate/quantity could improve the accuracy of reimbursement and streamline payroll by paying for precisely the weight of fruit harvested (K. Oliver, M. Omeg, and D. Hayden, personal communication).

\section{Conclusion}

Improving labor productivity is among the highest rated priorities articulated by tree fruit industries in Washington State. This is the result of its singular importance in production budgets and the heavy dependence on manual labor for fruit harvest. One of the most important factors affecting harvest efficiency of sweet cherry is the tree architecture. Here a novel LMS was used during commercial sweet cherry harvest to investigate the role of training system on labor efficiency. Our study suggested that canopy architecture has a major effect on labor efficiency. High harvest efficiency was documented in orchards with pedestrian and planar architectures with most fruit accessible from the ground. Furthermore, we discovered that harvest rate of less skilled pickers was reduced to a greater extent $(-67 \%)$ than skilled pickers $(-45 \%)$ when comparing efficiency in pedestrian and planar systems (e.g., UFO and KGB) with MLOC. These differences are likely the result of the fruit being highly accessible, much from the ground, and the placement of the ladder being consistent along the row (e.g., UFO).

\section{Literature Cited}

Ampatzidis, Y.G. 2010. Modeling and electronic monitoring of activities during manual harvested of specialty crops with application to precision farming and traceability [in Greek]. $\mathrm{PhD}$ thesis, Aristotle University of Thessaloniki, Thessaloniki, Greece.

Ampatzidis, Y.G., G. Tzelepis, and S.G. Vougioukas. 2008. A low-cost identification system for yield mapping during manual vine harvesting. Proc. of the International Conference on Agricultural Engineering \& Industry Exhibition, Hersonissos (Crete), Greece, 23-25 June.

Ampatzidis, Y.G. and S.G. Vougioukas. 2009. Field experiments for evaluating the incorporation of RFID and barcode registration and digital weighing technologies in manual fruit harvesting. Comput. Electron. Agr. 66:166-172.

Ampatzidis, Y.G., S.G. Vougioukas, D.D. Bochtis, and C.A. Tsatsarelis. 2009. A yield mapping system for hand-harvested fruits based on RFID and GPS location technologies: Field testing. Precis. Agr. 10:63-72.

Ampatzidis, Y.G., S.G. Vougioukas, and M.D. Whiting. 2011. An automated wearable system for real-time human position monitoring during manual fruit harvesting. Comput. Electron. Agr. 78:222-230.

Ampatzidis, Y.G., M.D. Whiting, B. Liu, P.A Scharf, and F.J. Pierce. 2012a. Portable weighing system for monitoring picker efficiency during manual harvest of sweet cherry. Precis. Agr. $<$ http://link.springer.com/article/10.1007/ s11119-012-9284-3>.

Ampatzidis, Y.G., M.D. Whitng, P.A. Scharf, and Q. Zhang. 2012b. Development and evaluation of a novel system for monitoring harvest labor efficiency. Comput. Electron. Agr. 88:85-94. 
Bowman, K.D. 2010. Longevity of radiofrequency identification device microchips in citrus trees. HortScience 45:451-452.

Brown, G.K. 2005. New mechanical harvesters for the Florida citrus juice industry. HortTechnology 15:69-72.

Burks, T., F. Villegas, M. Hannan, S. Flood, and B. Sivaraman. 2005. Engineering and horticultural aspects of robotic fruit harvesting: Opportunities and constrains. HortTechnology 15:79-87.

Cunha, C.R., E. Peres, R. Morais, A.A. Oliveira, S.G. Matos, M.A. Fernandes, P.J.S.G. Ferreira, and M.J.S. Reis. 2010. The use of mobile devices with multi-tag technologies for an overall contextualized vineyard management Comput. Electron. Agr. 73:154-164.

Kuflik, T., D. Prodorutti, A. Frizzi, Y. Gafni, S. Simon, and I. Pertot. 2009. Optimization of copper treatments in organic viticulture by using a web-based decision support system. Comput. Electron. Agric. 68:36-43.

Lang, G.A. 2005. Underlying principles of high density sweet cherry production. Acta Hort. 667:325-336.

Li, P., S.-H. Lee, and H.-Y. Hsu. 2011. Review on fruit harvesting method for potential use of automatic fruit harvesting systems. Procedia Engineering 23:351-366.

Luvisi, A., A. Panattoni, R. Bandinelli, E. Rinaldelli, M. Pagano, and E. Triolo. 2011. Implanting
RFIDs into Prunus to facilitate electronic identification in support of sanitary certification. Biosystems Eng. 109:167-173.

Luvisi, A., E. Trioloa, E. Rinaldelli, R. Bandinellib, M. Paganob, and B. Gini. 2010. Radiofrequency applications in grapevine: From vineyard to web. Comput. Electron. Agr. 70:256-259.

Morais, R., M.A. Fernandes, S.G. Matos, C Serodio, P. Ferreira, and M. Reis. 2008. A ZigBee multi-powered wireless acquisition device for remote sensing applications in precision viticulture. Comput. Electron. Agr. 62:94-106

Peterson, D.L. and S.D. Wolford. 2001. Mechanical harvester for fresh market quality stemless sweet cherries. Trans. ASAE 44:481-485.

Salehi, F., J.D. Whitney, W.M. Miller, T.A. Wheaton, and G. Drouillard. 2000. An automatic triggering system for a citrus yield monitor. Paper No. 001130. ASAE, St. Joseph, MI, USA.

Sanders, K.F. 2005. Orange Harvesting Systems Review. Biosystems Eng. 90:115-125.

Schueller, J.K., J.D. Whitney, T.A. Wheaton, W.M. Miller, and A.E. Turner. 1999. Low-cost automatic yield mapping in hand-harvested citrus. Comput. Electron. Agr. 23:145-154.

Seavert, C., J. Freeborn, and L. Long. 2008. Orchard economics: Establishing and producing high-density sweet cherries in Wasco County. OSU Extension Service Publication, EM 8802-E.
Seavert, C. and M.D. Whiting. 2011. Comparing the economics of mechanical vs. hand harvest of sweet cherry. Acta Hort. 903:725730 .

Strik, B. and G. Buller. 2002. Improving yield and machine harvest efficiency of 'Bluecrop' through high density planting and trellising. Acta Hort. 574:227-231.

Strik, B., G. Buller, and E. Hellman. 2003. Pruning severity affects yield, berry weight, and hand harvest efficiency of highbush blueberry. HortScience 38:196-199.

Tanigaki, K., T. Fujiura, A. Akase, and J. Imagawa. 2008. Cherry-harvesting robot. Comput. Electron. Agr. 63:65-72.

Whitney, J.D., Q. Ling, T.A. Wheaton, and W.M. Miller. 1999. A DGPS yield monitoring system for Florida citrus. Appl. Eng. Agr. 17: 115-119.

Whiting, M.D., G.A. Lang, and D. Ophardt. 2005. Rootstock and training system affect sweet cherry growth, yield and fruit quality. HortScience 40:582-586.

Whiting, M.D. and E. Smith. 2007. Mechanical harvest system has little impact on sweet cherry quality and storability. Good Fruit Grower 58:22-24.

Whiting, M.D. 2009. Upright fruiting offshoots Prosser, WA: WSU-IAREC. 8 Mar. 2011. <http:// fruit.prosser.wsu.edu/UFO.html>. 